\title{
CONVERGENCE OF HUMAN DEVELOPMENT INDEX: CASE STUDY OF FOREIGN DIRECT INVESTMENT IN ASEAN
}

\author{
M. Elfan KAUKAB $\mathbb{B D}^{*}$, Surwandono SURWANDONO \\ Postgraduate Faculty, Universitas Muhammadiyah Yogyakarta, Indonesia
}

Received 23 February 2020; accepted 21 April 2020

\begin{abstract}
This article examines the role of bilateral FDI and income convergence in affecting HDI increase in countries with middle HDI in ASEAN. The ASEAN Economic Community has been developing and it is expected that the gaps between nations can be covered. This article explores how economic intervention through HDI and income convergence can boost HDI improvement. The writers examine the presence of a statistically significant causal relationship between source country's GDP, home country's GDP, source country's FDI towards the home country, source country total FDI, home country total FDI, and the percentage of source country FDI towards source country total FDI with both countries HDI convergence. Measurement is carried out using the generalized method of moments. Based on yearly samples of high HDI countries (Malaysia, Thailand, Singapore) couple with medium HDI countries (Laos, Vietnam, Cambodia, Myanmar, Indonesia, and Philippine) during 2013-2017 period, the writers find statistically significant impact of home country GDP, source country FDI towards all countries, and FDI percentage of the home country compared to all countries.
\end{abstract}

Keywords: HDI, bilateral FDI, GDP, ASEAN, investment, economic development.

JEL Classification: F21, O15, P33.

\section{Introduction}

High HDI-Human Development Index, value is crucial for a country. The high value shows a country's capability in building its health sector and preventing its citizens from various health and survival issues (Černák, 2017; Khazaei et al., 2016). It is also an indicator of a country's ability to improve its human resource's quality and their general life quality (Rasool, 2017; Sunarya, 2017). Moreover, HDI helps to enhance a country's economic performance (Sinaga et al., 2018). HDI value is also important in perceiving the development quality and determining the policies taken by the government (Jednak et al., 2018; Sookias et al., 2018).

An important issue in HDI-related literature is identifying factors affecting a country's HDI (Sookias et al., 2018), especially factors affecting the components of HDI since some of its components have different characteristics such as GDP, educational level, and life expectancy. Literatures state that HDI or at least some of its components is determined by geographical factors such as natural transportation means and isolation, environmental variation like the climate in tropical countries, and sociocultural factors such as social norms, governmental management as well as society's cultural belief (Sookias et al., 2018).

Besides a country's internal factors, HDI is also influenced by other factors derived from society's international interaction. Previous studies (Ahmad et al., 2019; Ahmad et al., 2018; Ausloos et al., 2019; Iamsiraroj \& Ulubasoglu, 2015; Jude \& Levieuge, 2017; Nwaogu \& Ryan, 2015; Pegkas, 2015) have investigated the effect of FDI - Foreign Direct Investment, towards economic and HDI growths and found an important role of this variable in economic development. On the other hand, Egri and Tanczos (2018), Bucur andStangaciu (2015), and Asongu and Nwachukwu (2016) and Bunnag (2019) found a significant effect of income convergence on HDI. Income convergence is different than income or GNP per capita since income convergence derived from interaction of two or more components, namely income of home country and income of its pair country/countries. The difference is about absolutes and relatives form of income.

This research examines how bilateral FDI and income convergence affects the HDI in lower HDI countries. The overall aim of this research is to examine the effect of

*Corresponding author. E-mail: elvankaukab@yahoo.com

Copyright $\odot 2021$ The Author(s). Published by Vilnius Gediminas Technical University

This is an Open Access article distributed under the terms of the Creative Commons Attribution License (http://creativecommons.org/licenses/by/4.0/), which permits unrestricted use, distribution, and reproduction in any medium, provided the original author and source are credited. 
bilateral FDI and income convergence on HDI in lower HDI countries in ASEAN. The underlying research questions for this research are: (1) what bilateral FDI-related factors contribute to the HDI of lower HDI countries? (2) what income convergence-related factors contribute to the HDI of lower HDI countries? and (3) how do these variables influence HDI of lower HDI countries?

Only a few studies explore the impact of FDI and GDP on HDI in ASEAN countries. Whereas in line with the development of the ASEAN Economic Community, gaps between nations can be reduced in various ways, including economic intervention. Among the few studies is research conducted by Ahmad et al. (2019) that investigated the effect of FDI inflow to real GDP and HDI.

This research is different from the previous ones because we employ HDI convergence as the bound variable. HDI convergence is the HDI increase gap between two countries involved in investment, in which one is the source country while the other is the home country. A low convergence indicates that both countries are congruous in HDI increase, meaning that both countries have similar HDI increase. HDI convergence is measured by reducing the home country's increased HDI by source country's HDI increase. A positive value designates a larger HDI increase in the home country compared to the source country. This is highly expected because the home country in this research refers to the country with lower HDI compared to the source country. As an example, Singapore is a country with nearly maximum 100 of HDI, and thus, HDI increase here will be very low. Singapore is known as the main investor for other countries in ASEAN. Therefore, HDI increase in countries where Singapore invests will be positive. This is a better indicator than absolute HDI that considers neither the previous years' HDI nor investing country's HDI.

Low and medium HDI countries will benefit from this research because they will have a clear direction for opening foreign investment. It is also easier for high HDI countries for investing in low and medium HDI countries to gain overseas profit as the destination countries will make sure that their environment will conducive for foreign investment.

This writing is organized in the following way. Part 2 presents the literature on bilateral FDI, income convergence, and HDI convergence. Part 3 describes the data and methods used in the research. Part 4 provides empirical evidence through econometric analysis on FDI bilateral and income convergence to HDI in Southeast Asia. Part 5 is the conclusion.

\section{Literature}

The neoclassical growth theory states that FDI flows will boost economic growth (Ahmad et al., 2018). It will be reached as FDI encourages technological integration with local input, promotes cooperation with local enterprises, and helps human resources development. FDI flows are essential in enabling a low-technological country with limited human and organizational resources to catch up by moving towards convergence with a more developed country (Menon, 2013).

Furthermore, the neoclassical growth model asserts that in time, FDI effects on human, physical and employment resources will lead to human development (Mustafa et al., 2017). Freer markets tend to be more encouraging in enhancing growth and development if compared to an economic system run by the government (Keita, 2019). Research suggests that neoclassical economic method strongly relates to human development, defined as United Nations version of HDI (Terzic, 2018).

In line with this, ASEAN is an association of regional countries making efforts to free the markets through The ASEAN Economic Community initiatives. However, lowHDI ASEAN members are reluctant to join the ASEAN Economic Community as they regard their HDI is an obstacle to attract FDI (Thanh, 2016).

Nevertheless, FDI should be seen as a crucial factor in boosting HDI. Ahmad et al. (2019) found that FDI inflow in ASEAN countries and SAARC positively and significantly affect HDI. FDI inflow also relates to GDP increase (Ahmad et al., 2019), so GDP also affects HDI development. Egri and Tanczos (2018) confirms the strong and significant relationship between GDP and HDI in Eastern Europe, indicating economic and social convergence. This means that if countries in one region agree to have economic convergence, the positive impact will likely take place in social convergence through HDI convergence.

While the relationship between economic/income convergence in GDP and bilateral flow in FDI through social convergence through HDI might have a strong theoretical connection, there has never been any research aiming at investigating the effect of FDI and GDP on HDI in ASEAN.

Econometric model using convergence as the dependent variable or as predictor has been widely employed in the previous research, like the ones conducted by Lee (2018) and Dunne (2015). This research employs convergence as an approach to the research variables. The convergence concept, that means a situation in which an indicator in a less developed country grows faster than that of the more developed country, also derives from neoclassical growth theory (Jaros, 2019). There are three hypotheses related to convergence: absolute convergence hypothesis, conditional convergence hypothesis, and club convergence hypothesis (Egri \& Tanczos, 2018). Absolute convergence hypothesis states that a country with a low indicator will naturally converge with a country with a higher indicator. Conditional convergence hypothesis asserts that there are certain factors encouraging a low indicator country to converge with a high indicator country. Club convergence hypothesis asserts that the regional factor or cooperation group exists to make the group's members converge. This research follows conditional and club convergences. It conforms to conditional convergence 
because the researchers propose several factors affecting convergence, in this case, HDI convergence. The research complies with the club convergence as the phenomenon proposed takes place in one region, ASEAN.

\section{Econometric methods and data}

\subsection{Econometric model}

The effect of bilateral FDI and income convergence to HDI in Southeast Asia is empirically observed based on the following equation:

$$
\begin{aligned}
& \operatorname{Conv}(\mathrm{HDI})_{\mathrm{h}, \mathrm{st}}=\beta_{0}+\beta_{1} \operatorname{conv}(\mathrm{HDI})_{\mathrm{h}, \mathrm{st}-1}+ \\
& \beta_{2} \log (\mathrm{GDP})_{\mathrm{h}, \mathrm{t}}+\beta_{3} \log (\mathrm{GDP})_{\mathrm{s}, \mathrm{t}}+\beta_{4} \log (\mathrm{FDI})_{\mathrm{h}, \mathrm{st}}+ \\
& \beta_{5} \log (\mathrm{FDI})_{\mathrm{h}, \mathrm{t}}+\beta_{6} \log (\mathrm{FDI})_{\mathrm{s}, \mathrm{t}}+\beta_{7} \operatorname{conv}(\mathrm{GDP})_{\mathrm{h}, \mathrm{st}}+ \\
& \beta_{8}(\mathrm{FDI})_{\mathrm{h}, \mathrm{st}} /(\mathrm{FDI})_{\mathrm{s}, \mathrm{t}}+\mu_{\mathrm{h}, \mathrm{t}}
\end{aligned}
$$

In the equation, $\mathrm{h}$ is the index of the home country, $\mathrm{s}$ is the index of the source country, $t$ is the time in a year, HDI is Human Development Index, FDI is Foreign Direct Investment, GDP is Gross Domestic Product per Capita, conv is convergence, and log is the logarithm. The equation primarily contains three components namely the previous year HDI, GDP, and bilateral FDI. Bilateral FDI is counted as the FDI accepted by the home country from the source country. Other variables are the home country total FDI, source country total FDI, and FDI ratio spent by the source country to the home country with the total FDI spent by the source country to countries all over the world. This model is employed in Muhammad andKhan (2019) research.

Meanwhile, convergence in GDP is formulated as the following (Lee, 2018):

$$
\begin{aligned}
& \operatorname{Conv}(G D P)_{h, s t}=\left(\operatorname{logGDP} P_{h, t}-\operatorname{logGDP} P_{h, t-1}\right)- \\
& \left(\log \operatorname{GDP}_{\mathrm{s}, \mathrm{t}}-\log \log _{\mathrm{s}, \mathrm{t}-1}\right) .
\end{aligned}
$$

In line with this, convergence in HDI is:

$$
\begin{aligned}
& \operatorname{Conv}(\mathrm{HDI})_{\mathrm{h}, \mathrm{st}}=\left(\mathrm{HDI}_{\mathrm{h}, \mathrm{t}}-\mathrm{HDI}_{\mathrm{h}, \mathrm{t}-1}\right)- \\
& \left(\mathrm{HDI}_{\mathrm{s}, \mathrm{t}}-\mathrm{HDI}_{\mathrm{s}, \mathrm{t}-1}\right) .
\end{aligned}
$$

\subsection{Data collection}

Bilateral FDI data collection was carried out in the ASEAN FDI database (ASEAN, 2019). They were collected during the 2013-2017 period based on data availability. GDP data per capita based on PPP were obtained from Economic Outlook Database 2019 (IMF, 2019). HDI data were gathered from the UN (UNDP, 2019).

ASEAN has three HDI categories. They are very high HDI (Singapore, Brunei Darussalam, and Malaysia), high HDI (Thailand), and medium HDI (Philippines, Indonesia, Viet Nam, Lao PDR, Cambodia, and Myanmar). No ASEAN countries are in the low HDI category. The FDI data taken are FDI of very high HDI countries and high HDI and low HDI countries. Although the data has been around since 2013, since each data unit contains another 2 years, the analysis years began in 2013. The 2018 data are incomplete while the data for 2019 are not available just yet. Thus, the last year analyzed is 2017. As many of the values are empty and Brunei Darussalam does not possess complete data, the data is further reduced. The final number of data is 32 . Figure 1 shows the HDI convergence values of the medium HDI countries to high and very high HDI countries in the final year. Figure 2 displays the FDI of high and very high HDI countries in total (2015-2017).

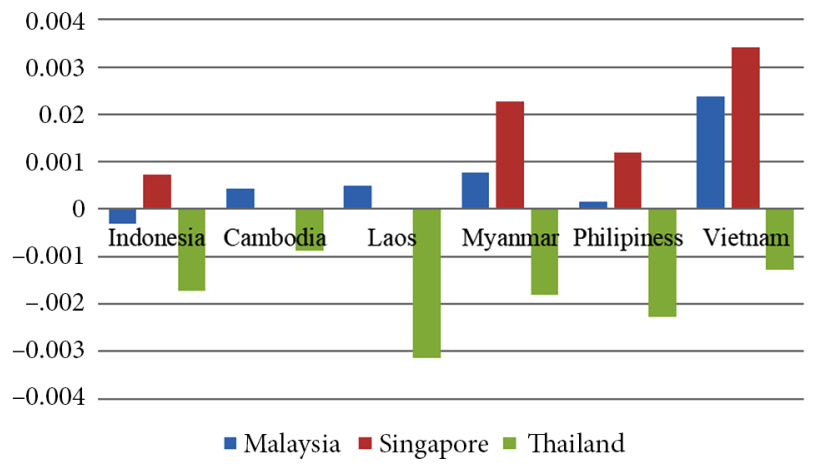

Figure 1. HDI Convergence of medium HDI countries to high and very high HDI countries in ASEAN

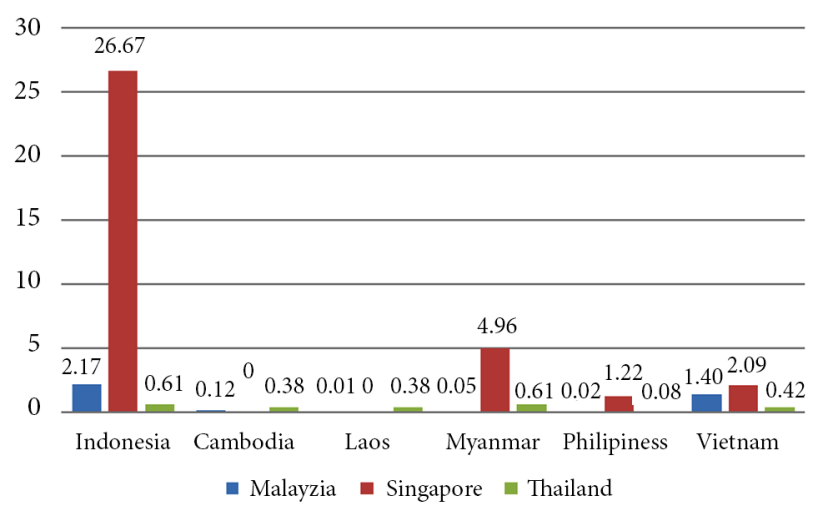

Figure 2. FDI Inflow of high and very high HDI countries to medium HDI countries in ASEAN 2015-2017 (in billion US\$)

\subsection{Data analysis}

Data analysis in this research employs the Generalized Method of Moments (GMM). The method is used to ensure data endogeneity. The estimated weighing matrix used is HAC, they are Bartlett kernel, Newey-West fixed with bandwidth 4 .

\section{Result and discussion}

Table 1 shows the system estimation. The estimated coefficient for three out of eight variables shows statistical significance. Estimated J-statistic reveals that the model possesses the right specification sine the prob value $($ J-statistic) $>0.10$. This indicates that orthogonality has been fulfilled. 
Table 1. GMM system (HDI Convergence)

\begin{tabular}{|l|l|l|l|l|}
\hline Variable & Coefficient & Std. Error & t-Statistic & Prob. \\
\hline X1: conv HDI t-1 & -0.018 & 0.090 & -0.207 & \\
\hline X2: log GDP home & -0.004 & 0.001 & -2.854 & *** \\
\hline $\begin{array}{l}\text { X3: log GDP } \\
\text { source }\end{array}$ & 0.001 & 0.001 & 0.823 & \\
\hline $\begin{array}{l}\text { X4: log FDI } \\
\text { bilateral }\end{array}$ & -0.000 & 0.000 & -1.102 & \\
\hline X5: log FDI home & -0.000 & 0.000 & -0.509 & \\
\hline X6: log FDI source & 0.003 & 0.001 & 2.780 & *** \\
\hline X7: conv GDP & -0.023 & 0.044 & -0.529 & \\
\hline $\begin{array}{l}\text { X8: FDI home } \\
\text { to total (world) } \\
\text { percentage }\end{array}$ & 0.010 & 0.003 & 2.645 & $* *$ \\
\hline$R^{2}$ & 0.69 & & & \\
\hline Adjusted R & 0.61 & & & \\
\hline J-statistic & & & 6.78 & \\
\hline Prob. (J-statistic) & & & 0.23 & \\
\hline
\end{tabular}

Note: Marginal significance level: ${ }^{\star * *}$ means $0.01 ;{ }^{* *}$ means $0.05 \mathrm{el}$.

The findings reveal a negative relationship between the home country's GDP with HDI convergence. This can be interpreted as an unsustainable development consequence that causes various HDI-related issues such as pollution and environmental damage. It confirms the findings by Adzawla et al. (2019). Meanwhile, Nyström (2008) and Noorderhaven et al. (1999) found that GDP increase lessens the community's entrepreneurial spirit and leads them to be low-paid employees. Another elaboration is given by Berik et al. (2009) stating that GDP increase leads to HDI decline as the development focus lies on high technology efficiency instead of work field addition in the home country.

Estimated FDI source (total) effect on HDI convergence shows that the increase of FDI source adds up HDI convergence, indicating that the country intensively doing FDI can encourage a medium HDI country in which it invests to have a raise. The result confirms that of Ausloos et al. (2019) and Jude and Levieuge (2017). This happens as the high FDI country possesses technology capacity, human resources development capability, and experience in building better business networks.

Estimation of FDI percentage of home to total shows positive coefficient. Therefore, the increase of HDI convergence is elaborated by a large focus given by the investor to the home country. In line with this, evidence exhibits that a high HDI source country's investment in medium HDI home country will encourage the HDI of the home country on a large scale.

As for the influence of previous years HDI convergence to current year HDI, the result indicates that there is no effect appear. HDI convergence depicts how big the HDI increases in the home country relative to the source country. Therefore, the absence of a significant relationship indicates that HDI achievement does not support each other year to year.
GDP source variable shows an insignificant degree. The source country's GDP does not affect the home country's HDI. In other words, economic advancement in the investing country gives no effect on welfare development in the invest-targeted country.

Estimation shows no significant relationship in terms of bilateral FDI. It is important to note that bilateral FDI in this study refers to the amount of investment by the source country in the home country. The result is different from what is expected. However, by considering the home FDI percentage variable to the total sum, it is revealed that the focus given to the home country plays a more important role instead of the amount of FDI. As previously explained, the home FDI percentage variable to the total sum significantly affects HDI convergence. Thus, FDI's role in increasing HDI derives from how big the economic bet made by high HDI country to medium HDI country (no ASEAN country is of low HDI). The amount of FDI flowing from the high HDI countries to medium HDI countries is also not considered. High HDI countries help their investors to get environmental support in medium HDI countries. They do it by encouraging medium HDI countries to increase their HDI. This leads to investing in medium HDI countries a priority, which indicates that HDI increase in medium HDI countries fulfils their mutual interests.

Evidence suggests that the home country's FDI does not significantly affect HDI convergence. As a result, the FDI done by home countries abroad does not influence their welfare. The only advantage comes from it is the needs-fulfilment satisfaction of the investing businessmen.

The estimated coefficient for GDP convergence reveals an insignificant relationship between the home country's GDP relative to the source country and home country's increased HDI relative to the source country. The insignificant connection is elaborated by the presence of GDP counterproductive effects. Thus, in some aspects, the source country's economic growth might cause environmental damage and socioeconomic gaps.

\section{Conclusions}

This research focuses on the analysis of ASEAN countries related to bilateral flow, economic convergence, and social convergence of six home countries, three of which are medium HDI and three high-HDI source countries. It employs the Generalized Method of Moments (GMM) with data from the 2013-2017 period. The result shows that home countries' GDP negatively affects HDI convergence, suggesting that the lower the home countries' GDP increases the gaps in home countries' increased HDI relative to the source countries. FDI of source countries to all countries and FDI percentage of source countries to home compared to all countries also show significant effect. The previous year HDI convergence, source country's GDP, the amount of source country's GDP to the home country, home country's FDI, and income convergence (GDP) do not significantly affect HDI convergence. This means 
that yearly HDI does not relate to each other. The investing country's economic development as well as its investment values, the amount of economic convergence and the home country's FDI to other countries do not contribute to the home country's HDI. Hence, FDI-related factors that contribute to the HDI of lower HDI countries are FDI of source countries to all countries and FDI percentage of source countries to home compared to all countries. Income convergence-related factors that contribute to the HDI of lower HDI countries is home countries' GDP. Home countries GDP and influence HDI of lower HDI countries negatively while FDI-related factors influence HDI of lower HDI countries positively.

The result implicates three things. First, the home country's GDP negatively affects HDI convergence. We suggest that medium HDI ASEAN countries improve their economic quality by paying attention to sustainable development principles. It can be carried out by providing work fields, encouraging entrepreneurship, boosting the creative industry and SMSE, and minimizing as well as mending environmental damage that leads to the community's welfare.

Second, the fact that source countries' FDI has an impact indicates that the source countries' investment quantity aids the HDI increase, even when not all of the FDI is invested in the home country. Therefore, we advise the home countries to provide wide opportunities for investors, especially those who come from high HDI countries. This might be obtained from technological transfer policy and joint venture partnership with investing companies to encourage increased HDI.

Third, the investment percentage of the source countries in the home countries to the total investment has a significant effect on HDI convergence. It is suggested that home countries should also pay attention to as well as provide easier investment opportunities for countries investing there. Ensuring the safety and conducive business climate in the home countries will be beneficial for both parties.

There are some limitations to this research. It only uses a small number of samples although still enables analysis as it has fulfilled the minimum requirement of 30 samples in regression analysis. Nevertheless, further research should add the number of samples to prompt more general and accurate results. The GMM method employed here also has its own weaknesses. We suggest that the following research employ other types of analysis and add robustness test method.

\section{References}

Adzawla, W., Sawaneh, M., \& Yusuf, A. M. (2019). Greenhouse gasses emission and economic growth nexus of sub-Saharan Africa. Scientific African, 3, e00065.

https://doi.org/10.1016/j.sciaf.2019.e00065

Ahmad, F., Draz, M. U., Su, L., Ozturk, I., Rauf, A., \& Ali, S. (2019). Impact of FDI inflows on poverty reduction in the ASEAN and SAARC Economies. Sustainability, 11(2565), 1-24. https://doi.org/10.3390/su11092565
Ahmad, F., Draz, M. U., \& Yang, S. (2018). Causality nexus of exports, FDI and economic growth of the ASEAN5 economies: evidence from panel data analysis. The Jourinal of International Trade \& Economic Development, 27(6), 685-700. https://doi.org/10.1080/09638199.2018.1426035

ASEAN. (2019). FDI by hosts and sources. https://data.aseanstats. org/fdi-by-hosts-and-sources

Asongu, S., \& Nwachukwu, J. (2016). The role of governance in mobile phones for inclusive human development in Sub-Saharan Africa. Technovation, 55-56, 1-13.

https://doi.org/10.1016/j.technovation.2016.04.002

Ausloos, M., Eskandary, A., Kaur, P., \& Dhesi, G. (2019). Evidence for gross domestic product growth time delay dependence over foreign direct investment. A time-lag dependent correlation. Physica A: Statistical Mechanics and Its Applications, 527(121181), 1-22. https://doi.org/10.1016/j.physa.2019.121181

Berik, G., Rodgers, Y. van der M., \& Seguino, S. (2009). Feminist economics of inequality, development, and growth. Feminist Economics, 15(3), 1-33. https://doi.org/10.1080/13545700903093524

Bucur, I., \& Stangaciu, O. (2015). The European union convergence in terms of economic and human development. CES Working Papers, 7(2), 256-275.

Bunnag, S. (2019). Income and HDI convergence in the mekong economies: regional development revisited. Social Science Review, 15-30.

Černák, J. (2017). Low fertility rate reversal: a feature of interactions between biological and economic systems systems. ArXiv Preprint, 1701.03481.

Dunne, P. (2015). Bilateral foreign direct investment from South Africa and income convergence in the SADC region. In TIPS Annual Forum. Johanesburg.

Egri, Z., \& Tanczos, T. (2018). The spatial peculiarities of economic and social convergence in Central and Eastern Europe. Regional Statistics, 8(1), 1-29. https://doi.org/10.15196/RS080108

Iamsiraroj, S., \& Ulubasoglu, M. (2015). Foreign direct investment and economic growth: A real relationship or wishful thinking? Economic Modeling, 51, 200-213. https://doi.org/10.1016/j.econmod.2015.08.009

IMF. (2019). World economic outlook database. https://www.imf. org/en/publications/weo

Jaros, K. (2019). Convergence of the standard of living in Polish NUTS 2 regions. Barometr Regionalny, 17(1), 15-30. https://doi.org/10.35480/BRAiP-2019.17.1-721

Jednak, S., Kragulj, D., \& Bulajic, M. (2018). A comparative analysis of development in Southeast European countries. Technological and Economic Development of Economy, 24(1), 253-270. https://doi.org/10.3846/20294913.2016.1212438

Jude, C., \& Levieuge, G. (2017). Growth effect of FDI in developing economies: the role of institutional quality. The World Economy, 40(4), 715-742. https://doi.org/10.1111/twec.12402

Keita, L. (2019). Models of economic growth and development in the context of human capital investment: the way forward for Africa. Africa Development, 43(3), 159-183.

Khazaei, S., Rezaeian, S., Khazaei, S., Mansori, K., Moghaddam, S., \& Ayubi, E. (2016). Effects of human development index and its components on colorectal cancer incidence and mortality: a global ecological study. Asian-Pacific Journal of Cancer Prevention, 17(sup3), 253-256. https://doi.org/10.7314/APJCP.2016.17.S3.253

Lee, S. (2018). Three essays on economic growth, country heterogeneity, and regime-switching. Univesity of Oklahoma. 
Menon, J. (2013). Narrowing the development divide in ASEAN: the role of policy. Asian-Pacific Economic Literature, 27(2), 25-51. https://doi.org/10.1111/apel.12025

Muhammad, B., \& Khan, S. (2019). Effect of bilateral FDI, energy consumption, $\mathrm{CO} 2$ emission and capital on economic growth of Asia countries. Energy Reports, 5, 1305-1315. https://doi.org/10.1016/j.egyr.2019.09.004

Mustafa, G., Rizov, M., \& Kernohan, D. (2017). Growth, human development, and trade: the Asian experience. Economic Modeling, 61, 93-101. https://doi.org/10.1016/j.econmod.2016.12.007

Noorderhaven, N. G., Wennekers, A. S. R. M., Hofstede, G., Thurik, A. R., Wildeman, R. E., \& Noorderhaven, N. (1999). Self-employment out of dissatisfaction: an international study (No. 99-089/3). Tinbergen.

Nwaogu, U. G., \& Ryan, M. J. (2015). FDI, Foreign aid, remittance and economic growth in developing countries. Review of Development Economics, 19(1), 100-115. https://doi.org/10.1111/rode.12130

Nyström, K. (2008). The institutions of economic freedom and entrepreneurship: evidence from panel data. Public Choice, 136(3-4), 269-282. https://doi.org/10.1007/s11127-008-9295-9

Pegkas, P. (2015). The impact of FDI on economic growth in Eurozone countries. Journal of Economic Asymmetries, 12(2), 124-132. https://doi.org/10.1016/j.jeca.2015.05.001
Rasool, M. (2017). Evaluation of life conditions in Middle East Region with focus on Bahrain. University of Pardubice.

Sinaga, O., Saudi, M. H. M., \& Roespinoedji, D. (2018). The relationship between economic indicators, Gross Domestic Product (GDP) and Supply Chain Performance. Polish Journal of Management Studiies, 18(1), 338-352. https://doi.org/10.17512/pjms.2018.18.1.25

Sookias, R. B., Passmore, S., \& Atkinson, Q. D. (2018). Deep cultural ancestry and human development indicators across nation states. Royal Society Open Science, 5(171411). https://doi.org/10.1098/rsos.171411

Sunarya, I. W. (2017). Analysis of human resources development in Province of Nusa Tenggara Timur From 2013-2015. Jurnal Aplikasi Manajemen, Ekonomi Dan Bisnis, 2(1), 22-30.

Terzic, L. (2018). The new paradigm of innovation economics in the 21st Century: solving the enigma of economic growth. Revista Romana de Economie, 1, 39-58.

Thanh, D. (2016). Direct investment in Vietnam from ASEAN countries in the context of AEC formation in 2015. Ekonomicke Trendy, 4, 62-75.

UNDP. (2019). Human Development Data (1990-2018). http://hdr.undp.org/en/data 